\title{
Articles \\ Map Room to Data and GIS Services: Five University Libraries Evolving to Meet Campus Needs and Changing Technologies
}

\author{
JEANINE SCARAMOZZINO and RUSSELL WHITE \\ California Polytechnic State University, San Luis Obispo, California, USA \\ JEFF ESSIC \\ North Carolina State University, Raleigh, North Carolina, USA \\ LEE ANN FULLINGTON and HIMANSHU MISTRY \\ New York University, New York, New York, USA \\ AMANDA HENLEY \\ University of North Carolina at Chapel Hill, Chapel Hill, North Carolina, USA \\ MIRIAM OLIVARES \\ Texas AGM University, College Station, Texas, USA
}

\begin{abstract}
Programs for geospatial support at academic libraries have evolved over the past decade in response to changing campus needs and developing technologies. Geospatial applications have matured tremendously in this time, emerging from specialty tools to become broadly used across numerous disciplines. At many universities, the library has served as a central resource allowing students and faculty across academic departments access to GIS resources. Today, as many academic libraries evaluate their spaces and services, GIS and data services are central in discussions on bow to further engage with patrons and meet increasingly diverse researcher needs. As library programs evolve to support increasingly technical data and GIS needs, many universities are faced with similar challenges and opportunities. To explore these themes, data and GIS services librarians and GIS specialists from five universities- the University of North Carolina at Chapel Hill, Texas A\&M, New York University, North Carolina State University, and California Polytechnic State University — with different models of library geospatial and
\end{abstract}

(C) Jeanine Scaramozzino, Russell White, Jeff Essic, Lee Ann Fullington, Himanshu Mistry, Amanda Henley, and Miriam Olivares

Address correspondence to Jeanine Scaramozzino, Robert E. Kennedy Library, California Polytechnic State University, San Luis Obispo, CA 93405. E-mail: jscaramo@calpoly.edu 
data support, describe their programs to help identify common services, as well as unique challenges, opportunities, and future plans.

KEYWORDS Geographic Information Services, GIS, GIS services, data services, reference, instruction, collections, outreach, infrastructure, spatial literacy

\section{INTRODUCTION}

GIS and data services in libraries have evolved in different ways and continue to adapt in order to incorporate new technologies and respond to changing universities' needs. Seeking to meet the unique needs of students and researchers at their home institutions, GIS and data services librarians and GIS specialists work continually to improve service models and devise strategies that integrate evolving technology and accommodate growing demand for geospatial resources. Although increasing demand for geospatial resources has been observed for several years, recent growth has come not only from established GIS users, but also from a widening breadth of disciplines interested in geospatial tools and resources. Evolving technology offers developments in Web-based and server technologies. These developments open new opportunities while raising challenges to provide infrastructure and administer sophisticated services. As university libraries grapple with these issues, they are often faced with similar challenges and opportunities.

Developments in library GIS services have been documented in the library literature over the past fifteen years. Included in the literature are efforts to capture both a broad overview of GIS services across institutions at a given time (Association of Research Libraries 1999; Kinikin and Hench 2005; Salem 2005) and detailed case studies of individual university programs, including their development, organization, and experiences (Sweetkind-Singer and Williams 2001; Houser 2006). Particular elements of GIS services are also highlighted by GIS services librarians in sharing their experiences, for example, opportunities for and importance of collaboration within and outside the university (Dixon 2006), collection development policies and evaluation (Florance 2006; Scarletto 2011), assessment of GIS needs across campus departments (March 2011), GIS staff skills and education (Weimer and Reehling 2006; Weimer 2008) and evaluation of GIS software (Donnelly 2010). In some instances, contrasting GIS service models from different institutions are presented together, such as the centralized and decentralized services at two universities described by Aufmuth (2006). Together, this literature provides a rich collection of experiences, lessons learned, and identified challenges from among the library GIS community from which program managers can learn as they continue to develop. 


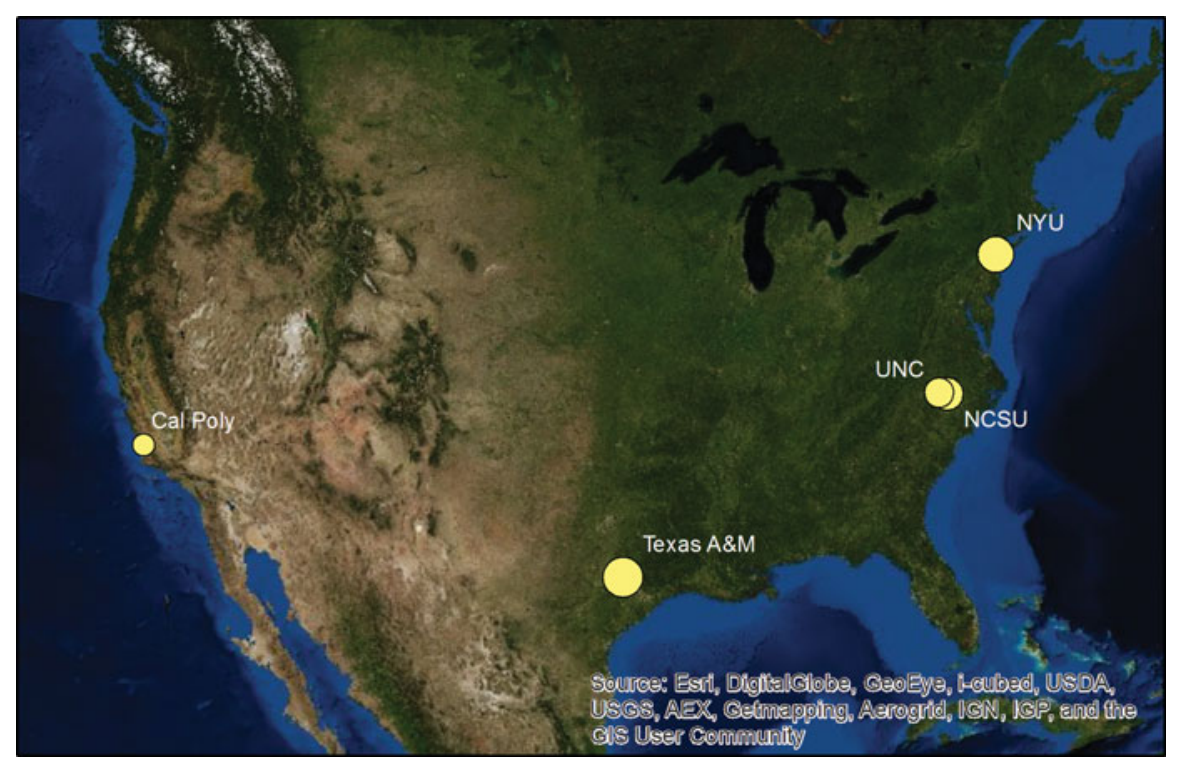

FIGURE 1 Location of Universities and Relative Size of Campuses.

Given the continued and rapid pace of GIS technology development, the shifting landscape of library services, and the unique campus settings served by different library GIS programs, incorporating these learned lessons from across institutions calls for a careful integration. No two programs are identical, nor are many of the constraints and challenges from merely five years ago still pressing when considering GIS service capabilities today. Contemporary descriptions of library services will continue serve as an important avenue of communication among developing programs. Previous special issues of the Journal of Academic Librarianship (Adler 1995; Adler 1997) and Library Trends (Stoltenberg and Parrish 2006) served as collecting points for the library GIS community and, similarly, updates to the current state of services in the present will be valuable in moving forward. The purpose of this paper is to document the stories of GIS and data services at five university libraries, specifically the development, current implementation, and future directions of GIS services.

GIS and data services librarians and GIS specialists from five university libraries-the University of North Carolina at Chapel Hill, Texas A\&M, New York University, North Carolina State University, and California Polytechnic State University-provide context for their campuses, general GIS use, and development of library GIS services, followed by discussion of computing resources, data discovery, access and archiving, and GIS services such as consultation, instruction, and outreach (Figure 1). Finally, each provides comments on the next steps and future vision for GIS and data services at their respective university libraries. 


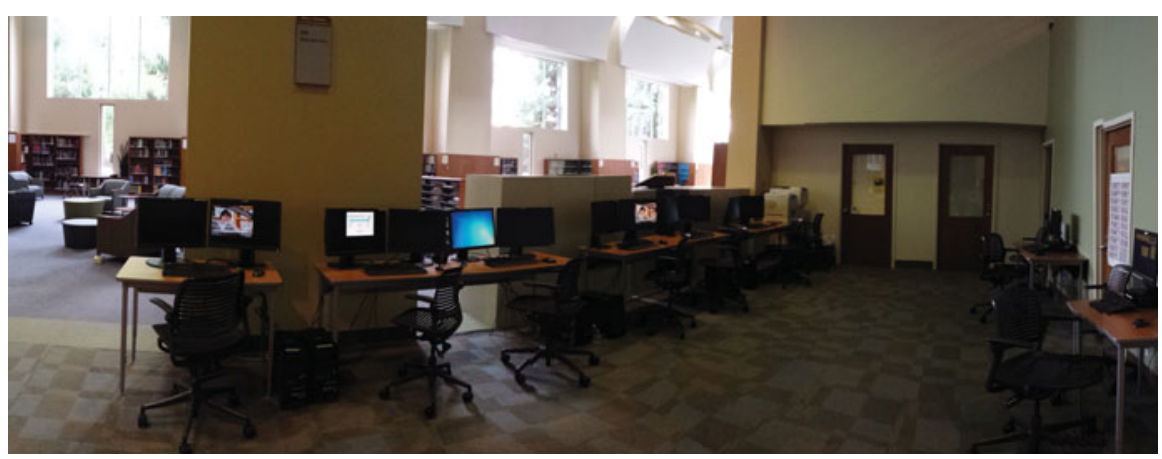

FIGURE 2 Walter Royal Davis Library GIS \& Data Services.

Data services librarians and GIS specialists from these universities have come together through networking at conferences such as the Esri Education GIS Conference, Google Geo for Higher Ed Summit, and others. Recognizing common interests and services, the group decided to continue conversations through a monthly conference call to learn more about the respective campuses and share experiences, challenges, successes, and resources. Through these conversations, the group has benefited from the perspectives of one another in providing data and GIS services at these respective universities. These universities vary in student and faculty populations, disciplines present on campus, and in the organizational structure of services and resources (Table 1). However, there is significant value in learning from others' processes and staying connected as a support network for information.

Each program discussed in this article could be written as its own paper, but discussing them collectively allows the reader to catch a glimpse across GIS and data services programs. Similarities in areas such as the importance of consultations, outreach, and collaboration with campus partners reflect common baseline services, whereas some differences emerge, reflecting unique campus needs and organization (undergraduate vs graduate, faculty research, disciplines, workloads). Emerging from these descriptions as well were different levels of detail and emphasis in describing areas of service. (Figure 2)

\section{UNIVERSITY SECTIONS}

GIS and Data Services at the University of North Carolina at Chapel Hill over the Past Ten Years: Responding to User Needs

About the University of North Carolina at Chapel Hill

The University of North Carolina at Chapel Hill (UNC) was the first state university, opening in 1795 . The campus is traditional, with 83.7 percent 


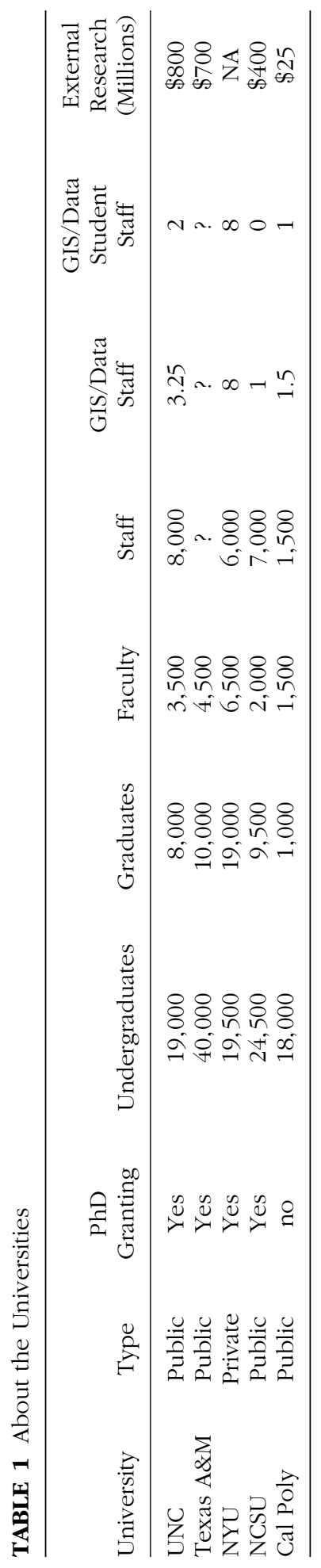


of the 29,278 students attending full-time. Graduate students comprise 28.2 percent of the students, and the university offers 66 doctoral and 102 master's degree programs. There are currently 3,608 faculty members, with the majority working full time. ${ }^{1}$ The University Libraries system is one of the premier library systems in the South, and it steadily ranks among top university libraries $^{2}$

There are a number of departments at UNC that offer courses and support for researchers who use spatial techniques. As of the fall semester 2013, seven GIS-focused courses are being taught to nearly 200 students, and many other courses have students use GIS for research projects or assignments. ${ }^{3}$ Most GIS courses are offered in the Department of Geography, but GIS is taught or used in many other departments as well, including Anthropology, City and Regional Planning, History, Ecology, Environmental Science, Marine Science, and Public Health. UNC also has a number of research centers and institutes that utilize spatial methods and data, including the Carolina Population Center and the Center for Urban and Regional Studies.

\section{GIS AND Data SERVICES}

The University Libraries is a distributed library system. The GIS and Data Services section is part of the research and instructional services department (formerly the reference department), located in the Walter Royal Davis Library (Figure 2 provides an image of the physical location.) Centrally located, Davis is the main library of the university. In addition to GIS and Data Services, the research and instructional services department also houses the government resources section and the Maps Collection. The university library is a Federal Regional Depository library. The need for a GIS librarian originally grew out of the government electronic documents section of Reference.

As spatial data sets from the Federal Depository Library Program increased, so did the need for a librarian having the skills necessary to understand and assist users with spatial data resources. The university library participated in the ARL GIS Literacy Project and subsequently hired a GIS librarian in 2002. The Maps Collection has never been under the GIS and Data Services section's purview, but because both are in research and instructional services, GIS librarians provide limited reference service for the Maps Collection, having worked with the librarian in charge of maps on workflow procedures for map digitization requests. Currently, three full-time librarians (two GIS librarians and one data services librarian) and two student assistants staff the GIS and Data Services section. The two GIS librarians provide GIS services to the entire campus and are subject librarians for geography and city and regional planning.

The data services librarian provides data services (primarily for social scientists) and data management services. All three librarians provide general 
reference service and are members of the Social Sciences Collections team. The GIS and Data Services section also benefits from a full-time support staff member working limited hours, whose hours are shared with technical services. This staff member has experience working with data and some statistics knowledge, so the library is experimenting with flexible scheduling to make the best use of staff expertise.

Given the wide range of GIS users at UNC, the library has served as an engaged neutral service provider since 2002. GIS services support computing, data, and other needs related to geospatial data and GIS techniques. UNC actively collaborates with other groups on campus to improve GIS services. The library maintains an e-mail list (uncgis), coordinates software offerings, and versions among computer lab managers across campus, and cohosts GIS Day events with the geography department. Over the past decade, a number of factors have shaped GIS services, including factors driven specifically by the university, the library, GIS technology, and technology in general. Among these driving factors has been an increase in GIS use on campus by a wide variety of departments, a move away from centralized computing labs on campus and toward virtualized computing, the adoption of a subject librarian selector model by the university library, and an ever-growing interest in online mapping applications and major improvements in storage and services in the cloud.

\section{COMPUTING}

The university is fortunate to have a software acquisition department within information technology services (ITS) that acquires and disseminates software to the campus. The software acquisition department manages the products available via the campus Esri site license, accessible under the University of North Carolina (UNC) systemwide site license. ITS also provides ENvironment for Visualizing Images (ENVI) software for image analysis and software for statistical computing. GIS librarians have cultivated a strong relationship with ITS staff that is mutually beneficial. Librarians provide outreach by promoting the software and accompanying resources, issuing virtual campus course access codes, and providing installation tips. ITS staff provides to librarians software and accompanying resources and the requisite permissions and access codes.

Since 2000, UNC requires all incoming undergraduate students to own laptop computers meeting university specifications. ${ }^{4}$ Accordingly, ITS has diverted resources away from physical computing labs to fund infrastructure and physical spaces that support laptop computing including networking, productivity, GIS, and statistical software offered remotely through the Virtual Lab, and work areas updated with laptop-friendly furnishings. ITS partnered with the university library to improve workspaces within libraries. 
Although the libraries still provide many publicly available desktop computers for look-up and productivity purposes, this number has declined noticeably in recent years in response to decreased demand. Some spaces that were previously filled with desktop computers have been transformed into comfortable spaces better suited to laptop use and group work. Users can access software applications on library computers or on their own machines via the Virtual Lab, which is platform-independent and can be used on a variety of client machines including desktops, laptops, and mobile devices. This is especially useful for the growing number of users who need to use ArcGIS but own Macs. Generally speaking, the Virtual Lab has increased the accessibility of software applications, but there are some minor complications for those users who choose to run the Virtual Lab on their personal machines.

In order to use the Virtual Lab, a receiver plug-in must be installed on the client machine. The Virtual Lab also requires an excellent Internet connection and typically runs slowly without one. Finally, there is a learning curve for new users who must understand how to access data sets stored locally on the client machine from within remotely hosted virtualized software applications. Users must also learn how and where to save output files to the local client machine. Because virtualized software is a novel concept to many, new users frequently require some instruction. These complications are largely avoided by those who run the Virtual Lab from library computers, which are preconfigured with the plug-in and have an excellent Internet connection.

The GIS and Data Services area in Davis Library offers six workstations devoted to GIS use. These workstations are set apart from other computing areas. Each GIS workstation is equipped with a high-performance tower desktop computer (replaced every other year) and dual, 22-inch LCDs. The library offers free letter-size color printing for maps. A suite of GIS and spatial analysis software is installed locally on each computer. Available software includes ArcGIS Desktop, ENVI, GME, Google Earth, GRASS (Geographic Resources Analysis Support System), QGIS, GeoDa, and R. Additional statistical software is available via the Virtual Lab. The GIS workstations receive high use, and consultations and walk-up assistance is provided in the GIS and Data Services area.

\section{Data-Collection, Discovery, Access, Storage, and Archiving}

Collection. The GIS and Data Services section acquires spatial and numeric data sets from a variety of sources. Initially, the budget for data purchases was limited, restricting capacity within the library for purchasing licensed data sets. The budget was used primarily to purchase value-added census data products from vendors that did not require license agreements. These products typically came on CD or DVD and required software installation on public computers in the library. Patrons had to come to the library 
to access the resources and had to use the software to extract data from the CD/DVDs, which generally required assistance from a librarian. Now, the library maintains access to Social Explorer, and directs users to the census Web site, the National Historical GIS Web site, or the Longitudinal Tract Data Base from Brown University for census data needs.

Subject librarians began doing collection development for the entire collection in 2010. The team-based subject selector model has provided greater flexibility in obtaining large purchases. Frequently used resources include ReferenceUSA (which the library subscribes to, along with an additional for-fee provision allowing users to download up to 500 business listings at a time), the National Establishment Time Series data for North Carolina, and foreclosure data by ZIP code for North Carolina from RealtyTrac. In recent years, the Acquisitions and Data Services staff members in the library have worked together to streamline the ordering of data sets as much as possible, and substantial improvements have been made in that area. There is now additional staff devoted to reviewing vendor license agreements. Librarians try to negotiate remote access to data sets whenever possible.

Discovery and Access. Cataloging spatial data at the level necessary to provide discovery of individual data sets has proven to be a challenge. For the past ten years, the library provided discovery of spatial data sets by means of a home-grown finding aid called the GIS Data Finder and provided access to the spatial data collection from campus, the Andrew File System (AFS). The GIS Data Finder was a database-driven Web site created using MySQL and PHP. It was keyword searchable. The records described data sets and provided the location of the spatial data files on campus AFS and the call number of the CD or DVD-ROM as appropriate. This discovery and access solution served its purpose well for a number of years, but it was not ideal. The GIS Data Finder was a data silo. The database was populated by data entry and therefore was labor-intensive, and because it was a local solution the work could not be shared with other GIS librarians. There has also been a move away from campus AFS for the storage of data sets. AFS was an excellent way to ensure authentication. Data access was convenient from computers in labs that mapped drives to the data automatically but was inconvenient for the growing number of laptop users because remote access requires (S)FTP or installation of an AFS client to allow drive mapping.

The library recently completed a multiphase, multiyear project to provide discovery and access to spatial data via the online catalog. With the help of the cataloging staff, MarcEdit software was used to batch convert FGDC metadata into MARC records for Esri Data and Maps holdings. For other data sets, catalogers created (at minimum) brief local records with emphasis on access fields-especially subject headings and keywords. The library uses 
the Endeca Information Access Platform for Libraries to customize and enhance the online public access catalog, which uses Millennium integrated library system software. Staff members from the library information technology department customized Endeca to provide a faceted and scoped search, limited to geospatial data. The search pages feature a chat widget (powered by LibraryH $31 p^{5}$ ) that connects users directly to GIS librarians for assistance finding spatial data, and catalog records display thumbnail images of geospatial data sets. The library now provides access to its data from a virtualized Web server, which is password protected to allow access to current affiliates only. Authentication is based on a centralized campus database; patrons can download the data directly from links in the online catalog. The final design, which was informed by usability tests, has been well received by the UNC GIS community. It includes a simple search box to initiate the geospatial data search, which is provided on the main GIS and Data Services page. ${ }^{6}$ The search box has been embedded in pertinent Libguides as well. $^{7}$

A large part of assisting in the discovery and access of spatial data is directing patrons to Web sites that provide spatial data. In the past, GIS librarians provided this assistance by creating and maintaining Web sites to list and describe spatial data sites. Sites with such lists quickly become difficult for users to navigate, and the ephemeral nature of data sites makes it difficult for librarians to ensure up-to-date, reliable links. To improve on the traditional page filled with links, librarians now maintain a collection of bookmarks to spatial data sites in Pinboard, ${ }^{8}$ a social bookmarking site. The collection of links is highly curated, and the links are tagged with ISO thematic categories and geographic identifiers. Pinboard provides link checking and caching of Web sites. It also allows for searching inside a link collection all at a relatively low cost. This solution improves usability and helps ensure accurate information for users. The library also maintains a Libguide to help users locate spatial data online. ${ }^{9}$ The Libguides content management system provides a link checker that can import and display information from RSS feeds. An RSS feed of links tagged "favorites" was generated from the uncgis Pinboard account and is now displayed in the Libguide, as is a tag cloud of ISO thematic categories. In this way, the Libguide is automatically updated when librarians add or edit links in Pinboard.

Storage and Data Archiving. The Carolina Digital Repository (CDR) provides long-term access to digital output from Carolina researchers and has a strong emphasis on preservation. ${ }^{10}$ Many papers are held in the CDR that were written by researchers utilizing spatial methods, including students and faculty in the departments of geography and city and regional planning and fellows of the Carolina Population Center. The CDR is suitable for the storage of spatial data sets and, although there are plans to add some in the future, there are none at this time. 


\section{SERVICES}

Consultation. Each year, the two GIS librarians in Davis Library provide approximately 400 research consultations. Consultations are defined by questions that require more than 30 minutes of a librarian's time, regardless of format (e-mail, telephone, in person, etc.). The demand for GIS services has grown steadily for a number of years and remains consistently high. Because this is such a busy service, an appointment-only policy has been instituted for meeting with GIS librarians, along with a system designed to facilitate consultation scheduling and time management. Three appointments are available each weekday to users who make reservations via a Web form on the GIS and Data Services Web site. ${ }^{11}$ The reservation form asks users to describe their research question to provide librarians the opportunity to prepare in advance, ultimately saving time for both users and librarians. The Web page reservation form is driven by a shared Google calendar and a free online service called YouCanBook.Me. ${ }^{12}$ In addition to the consultations offered by librarians, student workers offer walk-in assistance approximately ten hours each week. Over the past two years, there has been an average of 300 walk-in questions, and statistics show that walk-in hours later in the day or in the evening are much more popular than morning hours.

This system for scheduling consultations paired with the provision of walk-in help hours has improved the efficiency of GIS services. It provides librarians with a mechanism for time management, which is necessary to perform duties other than consultations. It also allows for referrals based on the level of assistance required by users and a clearly communicated service model that provides users equal access to GIS services. Finally, it encourages self-guided learning, which develops user confidence.

Consultation topics vary, but are often related to finding data, working with coordinate systems, and providing assistance to users who have hit a roadblock in their GIS projects or assignments. Beginner-level questions are referred to student workers as often as possible. Librarians often develop relationships with users and therefore know about their research interests and their level of proficiency with GIS technology. Librarians are also frequently consulted by faculty members and other researchers and are familiar with their needs. By staying abreast of research projects and courses being taught at the university and through the relationships they have built with users during consultations, librarians are uniquely qualified to match students with researchers who need GIS assistance beyond what the library can provide. Librarians have recommended specific students to faculty members looking to hire graduate research consultants ${ }^{13}$ to transform course work into research projects; they frequently post positions to the UNCGIS e-mail listserv. Engaged GIS librarians are well suited to provide this kind of matchmaking service. 
Instruction and Course Support. On average each year, the three librarians in GIS and Data Services teach approximately sixty instruction sessions. Much of the instruction is course specific, but the librarians also teach short courses on GIS or data management topics in collaboration with the Howard W. Odum Institute for Research in Social Science, also located in Davis Library. Instruction statistics have increased in recent years, which is attributed to instruction provided to courses in which instructors do not require the use of GIS per se, but they want students to include Web maps or visualizations for research projects or lab assignments. In recent semesters, librarians have provided this type of instruction for courses in communication studies, English, and history.

Course Support. In addition to instruction sessions, course support is provided in a variety of other ways. Data sets are fully accessible to students. Further, learning objects such as Web maps or virtual flash cards of geographic features are embedded in LibGuides to help students prepare for geography quizzes. In conjunction with faculty members, data sets, visualizations, Web maps, and apps have been made available to students on mobile devices to enhance courses with additional resources and technology. Librarians also work with faculty to refine or create assignments. One recent example is a librarian-created lab for an introductory GIS class that instructs students to georectify a digitized historical aerial photograph from the library collection. ${ }^{14}$ The library had purchased the digitized images from the USDA aerial photography field office. The expectation is that this collaboration will be mutually beneficial. Students were provided step-by-step instructions on how to georeference and rectify the aerial photos. Library officials would like to eventually provide the georectified images to other users, hoping that the idea of having their work benefit others might engage the students doing the assignment.

\section{LOOKING AHEAD}

Although ten years ago it would not have been possible to foresee GIS services at UNC as it currently exists, it is possible to plan ahead based on current trends and opportunities. Technology trends indicate that virtualized computing, Web-mapping applications, mobile and data collection applications, and open-source software will continue to shape GIS services. Library trends indicate that GIS and Data Services librarians will have the opportunity to participate in Research Commons initiatives.

Virtualized computing allows for greater flexibility in public computing. The library will likely move toward this model in the future as infrastructure improvements allow. This will streamline management of the GIS desktop image, provide more flexibility in adding and updating software, and allow for the deployment of GIS software and preferences optimized for GIS users to machines throughout the library. In addition to increasing 
the accessibility of GIS applications, this model is more responsive to user needs.

As Web mapping applications increasingly provide advanced GIS functionality and continue to gain popularity among users, it is likely that the library will expand services in this area. Included with the UNC site license for Esri software is an ArcGIS Online organizational account with a limited number of user accounts and service credits-the currency for ArcGIS Online. ${ }^{15}$ Now there are limited tools available within the ArcGIS Online platform to monitor or control the use of service credits by individual users on an organizational account. For this reason, GIS librarians have not advertised this tool widely, but have used ArcGIS Explorer Online with free user accounts for hands-on exercises in several classes with some success. Librarians are working to update these exercises for use with ArcGIS Online because ArcGIS Explorer Online is now a retired product. A variety of online mapping platforms are available; librarians have referred users to Google Fusion Tables, MapBox, and CartoDB, among others.

Trends indicate that GIS librarians at UNC will need to expand support to users with mobile mapping applications and data collection. The Media Resources Center located in House Undergraduate Library circulates iPads. A number of apps have been promoted to users including ArcGIS, Business Analyst Online, Health Data Finder from the World Bank, Google Earth, and ArcGIS Collector. To assist users with data collection, librarians have promoted the GPS import capabilities of Quantum GIS as well as online tools available from GPS Visualizer.

GIS services will continue to expand support for open-source software. Several open-source GIS software applications are currently installed at the public GIS workstations. Librarians have assisted with short courses on Quantum GIS and GRASS. Library GIS services will grow along with the availability of stable, well-documented, open-source GIS software.

Finally, as academic libraries build Research Commons and establish accompanying high-level research services, it is worth noting that these services parallel those offered within GIS and Data Services. Libraries is building Research Commons in order to provide the resources, space, tools, and expertise needed throughout the research process. These goals echo those that GIS and Data Services librarians have built into their service models over the past decade: providing effective workspaces, software, hardware, data sets, technological expertise and training, and connecting people in meaningful ways using their thorough understanding of users' skills and needs gathered through intensive research consultations. Libraries will be able to draw on the experience of GIS and Data Services librarians as they implement Research Commons and manage related services. 
The Map and GIS Library at Texas A\&M University: Serving the Needs of a Changing Academic Environment

\section{About Texas A\&M}

Texas A\&M University is one of three Tier 1 universities in Texas, with more than $\$ 700$ million spent annually on research. ${ }^{16}$ The student population as of 2013 is more than 50,000 students, which includes 10,000 graduate students ${ }^{17}$; they are guided by 2,800 faculty members and researchers, as well as 1,700 faculty members from the Texas A\&M Health Science Center. ${ }^{18}$ The scope of research themes is driven by the status of a land-grant, sea-grant, and space-grant public university, ${ }^{19}$ coupled with 120 undergraduate and 240 graduate-degree programs across ten colleges. ${ }^{20}$ Texas A\&M offers two graduate certificates in GIS and remote sensing. ${ }^{21}$ Close to two dozen of the GIS instructors teach more than thirty GIS and remote sensing courses. ${ }^{22}$ Some academic programs have compulsory GIS courses, and some that require geospatial analysis.

Texas A\&M has several research centers and laboratories housed within a few academic departments, which base their daily operations on geospatial technology. Established about forty years ago as a map room, the Map \& GIS Library is in a centralized location that provides geospatial support services and outreach to the GIS campus community. The Map \& GIS Library offers support not only to the Texas A\&M community, but also to the Texas A\&M Health Science Center and numerous state extension and research agencies of the Texas A\&M System. Patrons come primarily from geography, natural resources, planning, social sciences, earth sciences, and economics. The range and fields of study of those researchers seeking GIS help are increasing monthly.

\section{Geospatial Technology on Campus}

There are a select number of academic departments that lead the majority of research and teaching conducted with geospatial technology. The Department of Geography offers an undergraduate program in spatial sciences and a minor in geoinformatics. Their master's and doctoral programs offer opportunities to work with intense focus on geospatial science and applications. The department has two instructional labs with about twenty desktop computers each and a graduate geospatial lab with a half-dozen desktops, all offering GIS and various remote sensing software. Their recently opened Geographic Information Science and Technology Laboratory is equipped with more than a dozen computer stations with both GIS and remote sensing software, including open-source options and a multiscreen visualization board.

The university also has a number of other departments that are heavily involved in GIS research and teaching. The Department of Ecosystem Science and Management (ESSM) offers undergraduate and graduate degrees that include spatial sciences. Over ten years ago, ESSM partnered with the 
geography department to establish graduate certificates in GIS and remote sensing. ESSM houses the Spatial Science Lab (SSL), which is staffed by full-time associate and postdoctoral researchers as well as graduate and undergraduate students. Established over thirty years ago, the SSL is positioned as a preeminent interdisciplinary research center serving federal, state, and local agencies and the private sector.

The Department of Landscape Architecture and Urban Planning has ruled GIS mandatory for their undergraduate and graduate programs. Two GIS courses are offered; several courses require geospatial technology to perform the assignments and final projects. The GIS lab has a few dozen desktop computers with GIS, architectural, and visualization software. Six stand-alone, forty-two-inch monitors with integrated computers are available for individual or team usage.

The Department of Civil Engineering offers two GIS courses taught in a GIS lab with thirty desktops. Other academic departments such as Geology and Biological Engineering offer students equipment and software for the geospatial aspects of their work.

Texas A\&M holds a campus license for GIS software, which grants free licenses to all students. The availability of affordable software facilitates integrating geospatial technology with teaching, research, and self-learning endeavors. The university has thousands of desktops in dozens of open access labs (OAL) distributed across campus. Due to campuswide GIS licensing, all OAL desktops offer ArcGIS software so that every student, regardless of major, has access to the software. Faculty and campus-affiliated researchers also have access to the software. The Map \& GIS Library has been instrumental in enhancing the availability of GIS software. The deployment of GIS to all OAL computers was initiated by the Map \& GIS Library. Additionally, free licenses were provided to students who wanted to undertake self-learning and integrate geospatial analysis in their assignments and research. Previously, only students enrolled in a GIS course had the opportunity to obtain a GIS license to install the software on their personal computers. About 1,500 free licenses have been provided to undergraduate and graduate students since 2010 .

The Map \& GIS Library is situated within the main library, Sterling C. Evans Library, located in the center of campus. GIS instructors often request customized GIS sessions for their students. This service allows a close interaction between students and faculty members throughout the semester. Services are provided to users who request one-time support, whereas many other users become regular visitors while enrolled in their GIS course or for longer terms.

\section{SERVICES}

The Map \& GIS Library holds an extensive collection of printed maps with over 250,000 items. Additionally, the holdings include a vast collection of 
soil surveys, atlases, and geographic documents issued by the U.S. government, to name a few. These collections are a perfect complement to the GIS component of the library. The three overarching tasks performed in the library regarding GIS services are support services, outreach initiatives, and collaboration stations with large screen monitors.

In addition, there are numerous ongoing internal projects to enhance collections (i.e., creation of Web-mapping services and instructional materials). The library staff includes two library faculty members, the library coordinator and GIS librarian, and two professional staff members, a program assistant, and a GIS coordinator. The GIS team is formed by the GIS librarian, the GIS coordinator, and a group of four to six student workers with advanced GIS skills.

The GIS team develops students' skill base each semester and provides them the opportunity for real work experience. Employed students are given the job title of GIS consultant regardless of their academic level. Retention of highly skilled student workers has been improved by establishing a program of shared positions paid with funds from the library and interested academic departments, including Geography and Landscape and Urban Planning. The success of this program is due to both the department's benefiting from the training and supervision provided by the library and the fact that GIS services are offered in-house at their facilities during the work time they fund. The benefit for the Map \& GIS Library is the ability to offer a salary higher than the libraries' standard wage. A hands-on interview used in the hiring of students allows for a clear evaluation of their skills. These interviews enhance the technical skills offered to users, drastically reduce the need of geospatial training, and enhance the readiness of employed student workers to provide consultations on their own. Highly skilled student workers are ready to undertake complex internal projects such as Web-mapping services. Their involvement in interesting projects helps increase retention and attract outstanding candidates for job openings.

Consultation. The caliber of research conducted at Texas A\&M demands high-quality GIS support services. Inquiries from users range from assistance locating data sources to in-depth consultations for guidance on methodologies concerning geospatial analysis. Consultations regarding data range from simple requests of digital elevation models or U.S. census boundary polygons to complex data requests such as data mining of tweets with specific keywords (hashtags), race segregation by school district, historic street network (e.g., year 1970), and vacant parking lots in a metropolitan area. Common consultations concerning methodology have to do with geoprocesses such as geocoding, adding tabular data points using latitude and longitude (XY data), georeferencing scanned printed maps, network analysis, and joining tabular census data to census geographies.

To make consultation services efficient, a system of electronic appointments has been established and a data request form created. This form includes both map and GIS requests; it is provided to users when the data 
requests are complex and require more than a few minutes to find the right sources. The form includes a tracking system to learn who received it and when, if it gets transferred, and when the request is filled. To facilitate the location of data quickly by staff and users, the GIS team has created a thematic list of data sources such as land use/land cover, census data, remote sensing, and bathymetry. The team strives to locate data needed by researchers within 24 hours. A fast response rate for data location is in place, and the team has learned that becoming familiar with data sources and data reliability is highly helpful and reduces the need to acquire expensive data sets. Hence, the digital catalog is now growing at the pace of the list of data sources. However, if highly needed data sets that are not freely available are identified, internal proposals to obtain funds to purchase licensed data sets are submitted and are normally approved.

Instruction and Course Support. Another aspect of GIS support services is the training offered through seminars, hands-on training, and video tutorials created in-house. The themes of all the training provided are based on recurrent inquiries and new trends in geospatial technology with potential impact on the research conducted on campus.

Outreach. The outreach initiatives have a twofold objective: (1) to help advance research and (2) to help students increase their career opportunities by adding or enhancing GIS skills and spatial thinking. The outreach campaigns are conducted through resource fairs, student orientation events, open house events at the library, and GIS Day events. Around 2011, the GIS team began to receive feedback from students in the job market who realized the need for GIS skills after participating in career fairs or job interviews. To increase the number of students who learn about GIS before graduation, additional efforts were made to visit with classes from academic departments that traditionally do not expose students to GIS. Given the level of complexity in learning GIS desktop software, instruction sessions focused on Web-based GIS technology, which proves to be far easier for beginners.

\section{LOOKING AHEAD}

The Map \& GIS Library frequently revises the inquiries users bring to staff to solve. New questions and new data needs drive changes in services. It is critical to understand the fast-paced nature of geospatial technology and to be alert to changes that can improve efficiency in daily operations and facilitate the research and teaching endeavors embarked by the Texas A\&M geospatial community. An important technological change that has impacted the way digital collections are exhibited is seen in the transition from ArcIMS to Javaor Flash-based Web-mapping services. The new technology offers several new functionalities, including capabilities to share data, display memoryintense imagery, and create cartographically aesthetic interfaces. 
The growth of GIS users has increased the need for digital data. The GIS team facilitates the digitization of maps, drawings, and tabular data. Simultaneously, improvements in Internet technology aids in the proliferation of Web pages and interactive mapping services from federal, state, and local governments' providing a vast array of open-access data, with hundreds of different themes of geospatial and tabular data. Likewise, freely available imagery in virtual globes such as Google Earth, unveiled in $2005,{ }^{23}$ or Web data services such as Arcgis.com have reduced the number of requests from users to locate aerial or satellite imagery. All these technological advancements have reduced the need to acquire expensive data sets and allowed staff to focus on improving skills to locate relevant data.

With the fast-paced technology changes and the proliferation of digitized and digitally born data, the challenge of preserving and archiving the data must be faced. Librarians acknowledge the need to provide support and to curate, archive, and preserve geospatial data produced by researchers at Texas A\&M University and local government agencies. Curating and archiving relevant data collections in the university's institutional repository has been attempted with some success, as well as Web-mapping services developed in-house. As technology changes and memory-intensive data sets become available, the team will continue assessing the best way to preserve the data- and which platforms to use-for the benefit of the university communities and for the understanding of the world.

\section{Data Services at New York University: Responding to a Changing Research Environment}

ABOut New York University

New York University (NYU), one of the largest private universities in the United States, was established in 1832. The main campus (Washington Square Center) is located in Greenwich Village, close to the heart of Manhattan. NYU comprises fourteen schools, colleges, and divisions. ${ }^{24}$ The five major centers in Manhattan are Washington Square Center, Institute of Fine Arts (IFA), NYU School of Medicine, David B. Kriser Dental Center, and NYU Midtown Center. NYU Polytechnic School of Engineering in Brooklyn is home to the engineering and applied technology schools. Additionally, NYU has portal and satellite campuses throughout the world. The global degree-granting campuses include NYU Abu Dhabi and NYU Shanghai, as well as eleven international academic centers in Africa, Asia, Europe, North America, and South America. NYU has nearly 20,000 undergraduate students and approximately 19,000 graduate students, as well as more than 3,100 full-time faculty members. ${ }^{25}$ This section will detail the GIS services offered through Data Services, located at Elmer Holmes Bobst Library, the main research library at the Washington Square campus. Unless otherwise indicated, the information 
provided in this section is only about the Washington Square academic programs and does not include the School of Medicine, the Polytechnic Institute, or the Shanghai and Abu Dhabi portal campuses.

NYU does not have a geography department or a map division in its library system. Furthermore, the university does not have a specific geospatial program, though the recently established Center for Urban Science and Progress (CUSP) ${ }^{26}$ will have programs with spatial research components. Thus, NYU is in a unique position for providing GIS services. Currently, one to three GIS courses are offered per year at the Robert F. Wagner Graduate School of Public Service in urban planning, and occasionally for public health. In addition, there are about fourteen to seventeen courses across other departments that include GIS training in some form as part of instruction, visualization, or research.

Based on Esri software distribution, NYU has roughly $800+$ users of varying levels of interest and expertise. Users come from many disciplines, including anthropology, archeology, urban planning, urban design, politics, economics, social sciences, Irish studies, public health, epidemiology, food studies, real estate, education, biology, marketing, linguistics, dentistry, and social work. Though NYU does not have one department with a singular focus on GIS, there are a few intriguing ongoing projects at various NYU sites that incorporate maps and GIS tools.

The NYU IFA, with permission from the Egyptian Ministry of State for Antiquities, is involved in a large archaeological excavation project in Abydos, Egypt.

The aim of the Institute's efforts is to build a comprehensive understanding of the full range of ancient activity at the site, how this changed over time, how the meanings attached to the site were expressed and evolved, as well as how Abydos relates to the broader context of Egyptian history and culture. ${ }^{27}$

Students who take part in the Abydos excavations do digging, documentation, analysis, and mapping. The project uses a combination of GPS devices and a total station, along with high-resolution satellite images, to gather data, which are analyzed and visualized using GIS tools.

One of the highlights of the global technology services (GTS) boutique of GIS support to faculty is an undergraduate course called Where the City Meets the Sea: Studies in Coastal Urban Environments, which was taught jointly by two faculty members across two different continents and time zones in NYU Abu Dhabi and NYU New York. This marine urban ecology course used Esri ArcMap and Google Earth to manage, compare, and visualize geospatial environmental data for the two locations.

The Furman Center for Real Estate and Urban Policy, a joint research venture between the NYU School of Law and the NYU Robert F. Wagner 
School of Public Service, conducts active geospatial and empirical research in housing, land use, real estate, and urban affairs-primarily focused on New York City. The Furman Center produces the State of New York City's Housing and Neighborhoods, ${ }^{28}$ a yearly report that uses GIS tools for data analysis and visualization and compiles statistics regarding demographics, housing, and quality of life in the city's five boroughs. The center also collects a wide range of numeric and spatial data on the city's real estate market, such as the Subsidized Housing Information Project, ${ }^{29}$ and it makes the data public via their data search tool.

\section{GIS AND Data SERvices}

ITS originally provided limited quantitative services, and this small operation, run by one staff member, was based in an office adjacent to one of the student computer labs. This informal services set-up provided GIS support to an archaeological research team and several other researchers in a few disciplines by providing field equipment such as GPS units and laptops, software including ArcGIS and ArcPad, GIS expertise, and access to computers for geospatial analysis and storage of data, along with an ArcIMS setup. At that time, the demand, along with the visibility of the services, was not high.

In 2008, a team of visionary administrators from NYU Libraries and ITS came together and identified existing resources at NYU to start a dialogue for shaping data related services. This initial dialogue triggered a series of strategic conversations between ITS and Libraries, resulting in the establishment of a joint library-ITS facility, the Data Service Studio (DSS). The DSS had physical space, composed of staff offices and a lab/teaching space with ten PC workstations, in the Bobst Library, DSS started hiring full-time staff, including one faculty technology specialist to support GIS services and a few student assistants over consecutive semesters. DSS was charged with providing statistical and GIS services to students, staff and faculty, and these core services have not changed. GIS services then included a few introductory classes, one-on-one consultations, software distribution, guest lectures, and locating and providing available geospatial data. The exceptions to the services currently provided were large-scale printing and taking on departmental geospatial projects. These exceptions were short-lived as these services were deemed not scalable in light of the fast-growing geospatial demand and limited resources.

In November 2010, DSS was relocated to the Research Commons ${ }^{30}$ in Bobst Library. This newly created, shared space houses DSS (rebranded in 2012 as Data Services), ${ }^{31}$ the Digital Studio, ${ }^{32}$ Business and Government Information Services, ${ }^{33}$ and Coles Science Center, ${ }^{34}$ along with study areas optimized for laptop use and collaborative interactions. Through the relocation, DSS was expanded to a bigger lab footprint of 26 workstations. 
DSS, a unique, blended model of ITS and Libraries staffing and financing, flourished in this new location. The geospatial service demand grew multifold, with an ever-increasing number of service requests, class offerings, training requests, and software requests. DSS joined with the ITS software licensing team and desktop imaging team to automate software deployment on DSS workstations and give consistent and uninterrupted access to supported and nonsupported suites of software. This lab has twenty-seven-inch iMacs with Windows OS, so users have a dual boot option. DSS also started collaborating with the NYU Virtual Computer Lab to offer certain GIS software to provide greater accessibility of GIS software to students, especially those who do not want to install either GIS software on their PCs or Windows OS on their personal Macs. Furthermore, DSS also provides GIS software across the campus for personal academic use as well as in lab settings. In December 2012, DSS was rebranded Data Services to more accurately reflect the broad portfolio of services on offer with respect to data and research lifecycles.

\section{Data-Collection, Discovery, Access, Storage, and Archiving}

The NYU Libraries Spatial Data Collection is currently accessible through a Libguide that hosts the Spatial Data Repository (SDR). ${ }^{35}$ Depending on the file, the data sets can be downloaded in a zipped file or accessed directly through ArcGIS Desktop. For subscription databases such as Social Explorer, Simply Map, and Digital Sanborn Maps 1867-1970, users can authenticate through Libraries' databases links on its Web site. For GeoLytics, users can access the tools through the library catalog, BobCat, as these resources have been cataloged (MARC records). In order to access New York State GIS Clearinghouse data sets, users need to make an appointment with Data Services for assistance. Relevant public GIS data sources have been linked on the Libguide for NYC and Metro Area Spatial Data (Bytes of the Big Apple, CUGIR, NYC Information Technology and Telecommunications, New Jersey GIS Network), United States Spatial Data (CrimeStat, GeoData.gov, Tiger Files, American FactFinder, GeoLytics, U.S. Geological Survey, National Historical Geographic Information System), and World Spatial Data (GIS Data Depot, Map Library, OpenStreetMap).

The SDR team is composed of seven members from both Libraries and ITS, and after little more than a year of work, the SDR was launched in August 2011. The SDR houses over 145 data sets, of which many draw from Esri data and popular public New York City data, including NYC Streets (LION) and NYC Community Districts. The SDR, despite being in an evolving state, saves users an in-person visit to Data Services, as this is a self-service, one-stop shop for public and NYU-subscription-licensed data sets.

Search and discovery of spatial data is a major challenge. Data Services is looking into collaborating with OpenGeoportal.org-an open-source tool 
developed by Tufts, Harvard, and MIT to discover, preview, and access geospatial data from various participating organizations. NYU is currently exploring new options for storing and accessing spatial data.

\section{COMPUTING}

Data Services supports GIS and mapping software: ArcGIS Desktop, ERDAS Imagine, GeoLytics, Google Earth, and Google Earth Pro. Librarians support Simply Map, Policy Map, and Social Explorer. Data Services works closely with the ITS software licensing team and desktop imaging team to automate software deployment on its workstations and to give consistent and uninterrupted access to a supported and nonsupported suite of software, including GIS software.

Regarding Esri software licensing and Virtual Campus courses, the NYU Software team (part of ITS, not part of Data Services) handles maintenance of the Esri site license. Everything else regarding the software is handled by the senior academic technology specialist at Data Services. These responsibilities include disseminating ArcGIS software-making student copies, handling installation issues, provisioning files for professional ArcInfo licenses, providing concurrent licenses, and making sure it is updated throughout the campus and provisioning for any extensions and other licenses. The senior academic technology specialist also processes the codes for Virtual Campus courses.

\section{SERVICES}

Consultation. Data Services staff provide consultations for GIS queries, software, and geospatial data requests. Most of the consultations are handled via e-mail and appointments, followed by walk-ins and telephone queries. Usage statistics gathered by Data Services suggest a steep growth in number and type of GIS queries since its inception (see Figures 3 and 4). ${ }^{36}$ GIS queries come from almost all disciplines and schools at NYU. Graduate students constitute the major clientele, followed by faculty, staff, and undergraduate students. In addition to Data Services, NYU's GTS also provides GIS services to a select few faculty members, specifically in course development, who want to incorporate geospatial tools for instruction.

Librarians on the Research Commons are familiar with Simply Map and Social Explorer, and they can take these consultations to relieve some of the GIS technology specialist's workload. Moreover, the cross pollination of GIS interest with the librarians has broadened the scope of services for Data Services because the GIS technology specialist can call on librarians who have some experience with ArcGIS and find spatial data to help out with the overflow of users. At NYU, the GIS senior technology specialist and the librarians on the Research Commons have cultivated collegial relationships. Librarian 


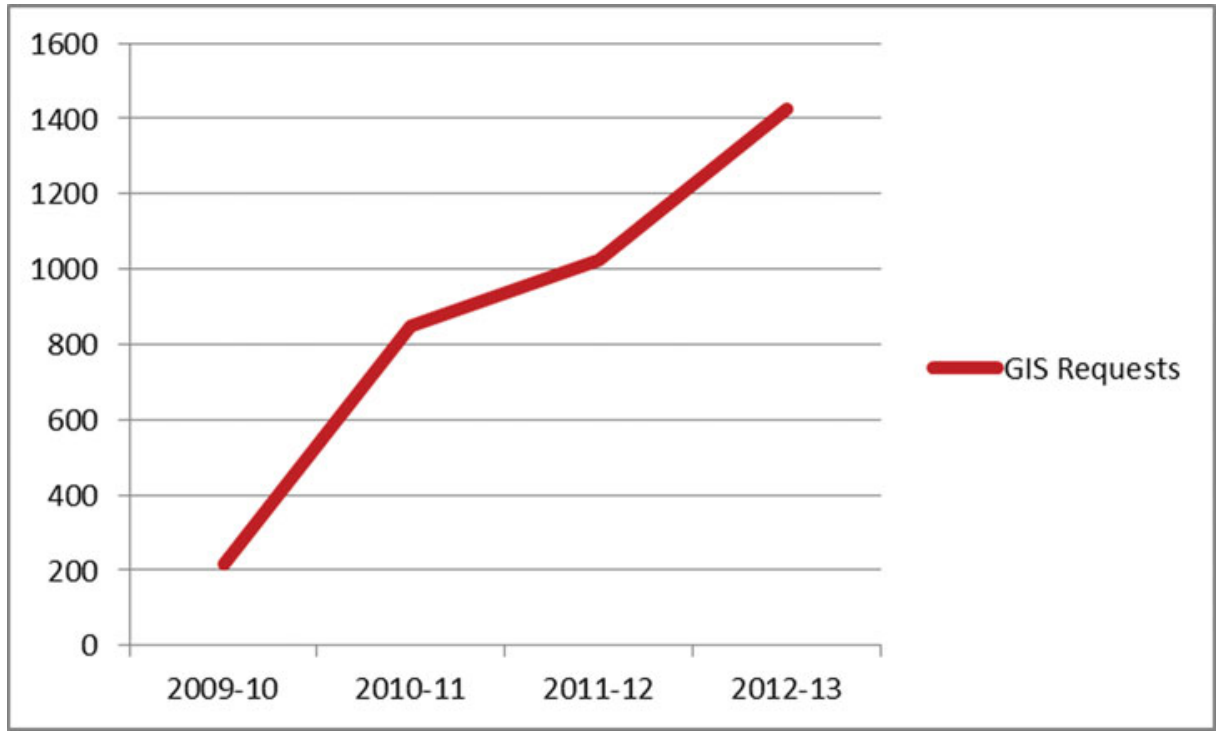

FIGURE 3 Number of GIS Requests 2009-2013.

enthusiasm for using GIS tools is growing because of this atmosphere that is conducive to collaboration and learning from one another.

Instruction and Course Support. Data Services provides instruction in various ways, such as regularly scheduling and conducting several

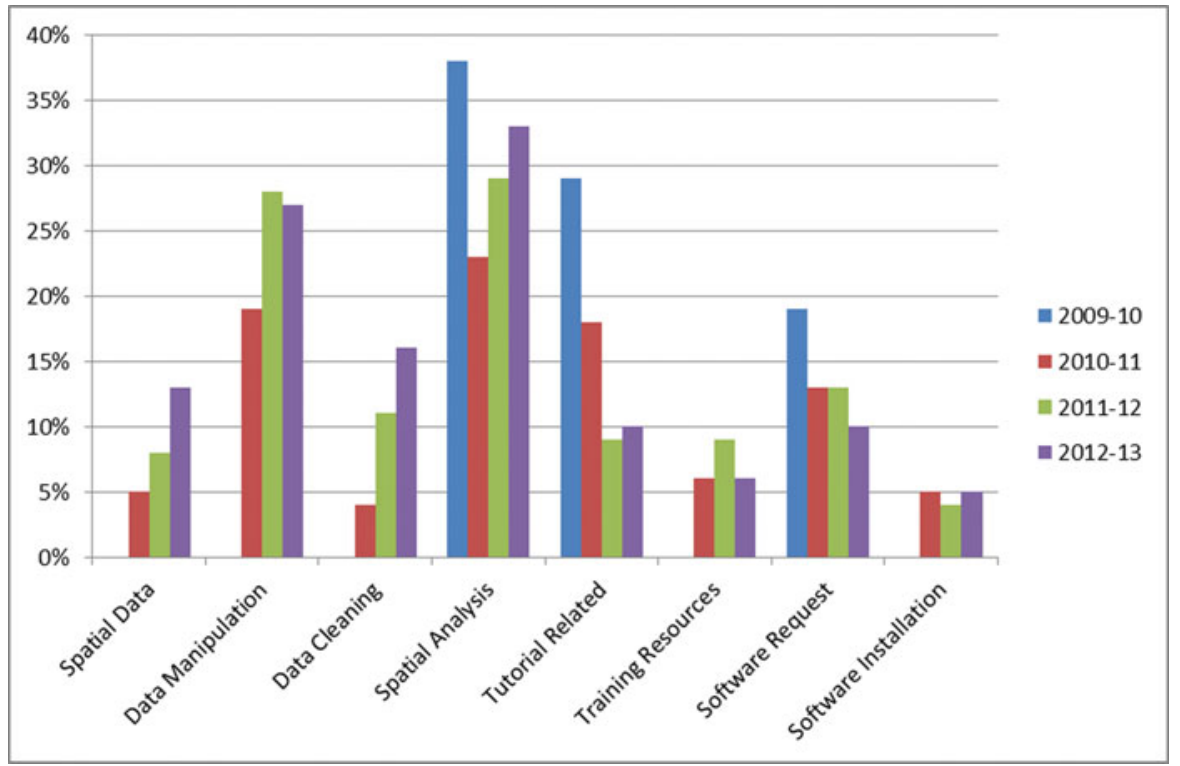

FIGURE 4 Requests by Type Between 2009-2013. 
introductory classes for the supported software. These classes are free to NYU students, staff, and faculty, typically lasting between 60 and ninety minutes. Data Services gathers statistics about classes offered and number of attendees. Low or no attendance is, of course, a concern. Regardless, the number of classes offered and the attendance has grown steadily over the four years. In several instances, introductory, specialized, or customized classes were also conducted on request by faculty, staff, or student groups. More and more faculty members are approaching Data Services to incorporate a GIS module in their coursework. The latter two scenarios ensure 100\% attendance rates.

Outreach. So far, this service model has worked well for reaching out to numerous users throughout NYU, as the GIS staff is in direct contact with GIS users. The software is distributed where services are being provided rather than from the back-end IT shop, where a lot of meaningful interactions and connections could be missed. In other words, the users not only get the software, but also learn about GIS services and where to get further GIS assistance. This gives Data Services and librarians many opportunities to assess and serve users in meeting their needs. Data Services has since gained credibility as a personalized one-stop-shop GIS service. The Esri software distribution, along with Virtual Campus courses, has increased well beyond offsetting the cost of the site license.

Data Services is located on the Research Commons, along with the Digital Studio (support for media technologies and digital scholarship), Business and Government Information Services, and the Coles Science Center (science reference). The colocation of these departments has contributed to collaboration between the GIS senior academic technologist or the data services librarian and reference librarians and reference associates in business and science, the better to serve users. Joint consultations between librarians or reference associates and the GIS senior academic technology specialist are not only time saving for the user, but also play to the strengths of librarians and technology specialists.

Data Services and the Coles Science Center joined in 2012 to host the first GIS Day celebration at NYU. The senior academic technologist and the sciences reference associate took the lead in the planning the event, which encompassed most of the Research Commons for part of the day. Because NYU has no logical location for GIS services with the absence of a map library or geography department, Data Services, and by extension the Research Commons at Bobst Library, is the most logical place at NYU to house GIS. To draw attention to the GIS services at Data Services and to highlight the library as the hub for GIS on campus, GIS Day@NYU brought the GIS community at NYU together in one place. The event featured large, colorful posters of maps created by students in various courses cascading from the ceilings and on the walls throughout the Research Commons. The event also had information booths for various projects and departments, including the IFA Abydos project, the Furman Center for Real Estate and Urban Policy, 
and representatives from Data Services and librarians showcasing services, including the SDR, Simply Map, and Social Explorer. Also, the event had a "faculty corner" where attendees could chat and network with faculty members who use GIS tools in their courses and research. The event was lively and well attended, with more than one hundred — and which platforms to use - people stopping by to find out more about GIS, mapping, and spatial data services and projects across NYU.

\section{LOOKING AHEAD}

Since the establishment of DSS in 2008, Data Services has seen a greater than 600 percent increase in GIS software demand, along with an accompanying growth in requests for in-depth consultations and queries from a wider spectrum of disciplines and subject areas. As mentioned earlier, the number of courses incorporating GIS has increased from three to seventeen, representing various departments and subject areas. NYU has begun offering an additional three or four new graduate degree programs in quantitative research methods, which include GIS as one of the components. CUSP, a unique public-private research center that NYU, along with a consortium of world-class universities and prominent international tech companies created, will observe, analyze, and model cities and huge data sets to inform, guide, and influence various policies, thereby adding to GIS demand.

Given such forces, Data Services is looking to expand and enhance its services in a few different areas. Data Services and Libraries are seeking additional staff, including a GIS librarian and an adjunct GIS specialist. The GIS librarian will be responsible for collection development, spatial data curation, outreach, and instruction, to complement the technical expertise of the GIS senior academic technology specialist. Data Services is looking into various outreach strategies and developing GIS Lite tools to serve a much larger audience. Data Services is also collaborating with GTS to provide a wider range of geospatial services to faculty and students across NYU's portal and global campuses. In addition, Data Services is planning on providing more in-depth and subject-specific GIS training along with expanding the array of GIS software support. Last but not least, Data Services will reevaluate its Web site and consider revamping it or finding a more effective online model for dissemination and delivery of GIS services and information.

Answering the Call for Data Services-North Carolina State University About North Carolina State University

North Carolina State University (NC State) is located in Raleigh, North Carolina, and has the largest higher-education student enrollment in the state 
with over 34,000 students. ${ }^{37} \mathrm{NC}$ State is a land-grant institution, with strong concentrations in agriculture, engineering, forestry, design, natural sciences, education, business, and social sciences.

The university is served by the D.H. Hill Library on the main campus, along with three branch libraries serving colleges and departments in select locations. In January 2013, the James B. Hunt Jr. Library was opened on the Centennial Campus, approximately one mile from the main campus, as a signature and iconic building within a rapidly developing, technology-rich environment. The Hill and Hunt libraries, as well as the branch libraries, collectively named the NCSU Libraries, are highly treasured assets among students and faculty, and have been leading the evolution of academic libraries worldwide in providing technology-rich services and learning spaces to campus communities. An early, successful example of Libraries' delivery of services for emerging technologies is the development of the geospatial data program that began in 1992, when the NCSU Libraries became one of the original participants in the Association of Research Libraries GIS Literacy Program (Morris 1999).

Generally speaking, academic research using GIS is present at NC State in varying degrees in almost every college and in many, if not most, departments. The largest concentration of GIS activity takes place in the Center for Earth Observation (CEO), located in the College of Natural Resources. In May 2013, a new Geovisualization Laboratory was opened in the CEO that features interactive and multitouch displays, a high-resolution $3 \mathrm{D} / 4 \mathrm{~K}$ projector, an immersion system, a tangible GIS system, ocular tracking hardware, and other high-tech collaboration spaces. ${ }^{38}$

In conjunction with the $\mathrm{CEO}$ and located within the Department of Marine, Earth, and Atmospheric Sciences, Drs. Helena Mitosova and Laura Tateosian manage an Open Source Geospatial Research and Education Laboratory through a partnership with the Open Source Geospatial Foundation and the International Cartographic Association. ${ }^{39}$ GRASS and other open source packages are used extensively by these researchers and their students to model, visualize, and teach topics related to natural processes, such as beach and sand dune erosion and sea level rise.

Under the leadership of NC State's chancellor, Randy Woodson, the university began an initiative in 2011 to advance its level of research and scholarship in strategically important areas through an effort of hiring highly accomplished faculty members with a diversity of skills. Geospatial analytics was identified as one of the twelve disciplinary cluster areas. ${ }^{40}$ This recognition of the importance of geospatial technology and commitment of university resources toward its vitality is a remarkable milestone.

Most GIS courses available at NC State are administered through the Center for Earth Observation. Two graduate-level degrees and two minors 
are offered. The establishment of a $\mathrm{PhD}$ program is likely to emerge in the not-too-distant future.

According to the CEO's Web site, http://gis.ncsu.edu, there are twelve courses in the core Geospatial Information Science and Technology master's curriculum. All students begin with GIS 410/510, titled Introduction to Geographic Information Science, which had a Fall 2013 enrollment of 210 students, 104 of whom were enrolled through Distance Education. ${ }^{41}$ Additionally, there are about thirty-five courses offered across campus in which GIS is a significant component of the instruction, including such topics as database management, precision agriculture, digital image processing, public administration, landscape evolution, and spatial statistics.

\section{GIS AND DATA SERVICES}

From the beginning, data services provided by NCSU Libraries have functioned as an umbrella for bringing together the multiple disciplines engaged in GIS activity on campus. Libraries serves this role by providing extensive data collection, Web-site, software support, outreach, and communication channels.

NCSU Libraries has one data services librarian (DSL) within the reference and information services (RIS) department. The DSL also manages Libraries' map collection and is the Federal Depository Library Program contact person for government documents.

\section{COMPUTING}

In the Learning Commons at the D.H. Hill Library, two multipurpose GIS computers are provided for all patrons, as well as one in the Hunt Library on Centennial Campus. The computers operate with the Windows 7, 64bit operating systems, Intel Core i7 $2.8 \mathrm{GHz}$ processors, 8GB of RAM, 1TB hard drives, and either dual or extra-wide monitors. The computers are used heavily for consultations, student assignments, and research projects. The full list of their software is maintained online. ${ }^{42}$

NC State has a campuswide educational site license from Esri, and ArcGIS software is available throughout campus in every computing lab. Installation files are also available for download from the campus software Web site, managed by the Office of Information Technology (OIT). ArcGIS can be installed on any university or personal computer of an NC State affiliate, as long as authentication to the license server can be made. The DSL collaborates with OIT on various software issues and has Esri's permission to submit technical support questions on behalf of NC State affiliates. 
Data-Collection, Discovery, Access, Storage, And Archiving

Much of the research at NC State, as a land-grant institution, is focused on locations within the state of North Carolina. Thus, data relating to North Carolina are the top priority for acquisition, and data with an extent completely outside North Carolina are acquired only by patron request. The DSL strives to obtain data that relate to North Carolina geography, are not easily accessible elsewhere, are at moderate to high risk of not being accessible in the future, or possess moderate to high academic value.For example, typically only compressed three-band orthoimagery is provided online, while the uncompressed four-band version is usually needed by researchers.

One of Libraries' most extensive collections is the county and municipal government data archive. The data include both vector data layers and raster orthophotographs, and they are regularly requested for temporal analysis. The archive contains the only documented copy of some counties' data for certain time periods. Over the past decade, local data have been acquired at a variety of different times and in various ways, resulting in a highly fragmented collection up to the present, but that is changing as numerous statewide data collection efforts are providing aggregated and standardized local content.

Currently two file servers store the data repository. One server contains 2.8 terabytes of data and is accessible from any campus computer or off campus through NC State authentication. The other server contains 7 terabytes of data-mostly orthophotographs-and is accessible only to the DSL. Nearly all the data acquired for the past fifteen years are stored on these servers. The data are cataloged through the GIS Lookup database, which was developed in-house and is reached through the Data Services Web site.

Local data are cataloged only by acquisition date; these dates are listed by county through the local links directory athttp://www.lib.ncsu. edu/gis/counties.html. Additionally, this directory page links to local GIS Web pages, map servers, and data download sites. The directory page consistently ranks as one of the most visited Web pages on Libraries' Web site, and it is heavily used by nonaffiliates. In fact, for the twelve-month period November 2012-October 2013, it is ranked eighth for the total number of page views $(160,359)$ and is the fourth highest landing page $(56,327$ entrances), according to Google Analytics.

In early 2012, an External Data Sources section was added to the results page of the GIS Lookup that leverages API access of several prominent GIS-data clearinghouses. After entering a search term, the user will see the number of matching data sets and the top three relevant hits from each clearinghouse site in the External Data Sources box.Currently linked data sites are NC OneMap, geo.data.gov, ArcGIS.com, and the WeoGeo Market, while query-loaded links point to a few other sites. The technical aspects 
involve using PHP to parse RESTful, JSON, or XML text strings returned by the APIs. This additional search results window exposes users to data sources they may not have otherwise discovered, and it saves the user the effort of querying each Web site individually. Google Analytics has been tracking the number of clicks on each source and the specific search terms since July 2012. Since that time through October 2013, there have been over 9,500 clicks on the external data sites.

SERVICES

Consultation. Most DSL's patron interactions are with graduate students, followed by faculty and non-NC State affiliates. A relatively large number of nonaffiliates, either from other universities or the general public, make contact because NCSU Libraries' Web pages are frequently one of the top hits for their GIS data Web search. Most reference assistance is delivered by the DSL via e-mail. During the period July 1, 2012-June 30, 2013, 515 email reference conversations were conducted, and there were seventy-seven in-person consultations and seventy-two reference-related phone calls. There is no clear trend in the growth or decline of these reference statistics for the past eight years.

The DSL maintains a comprehensive Web site at http://www.lib.ncsu. edu/gis that is devoted to GIS data sources, providing thorough documentation and discussion of the data repository. Reports created with Google Analytics reveal that in the twelve-month span between November 2012 and October 2013, the /gis/ subfolder of Libraries' Web site has served the fourth highest number of pageviews for the entire site, at 673,552.

Instruction and Course Support. Each semester, two sessions of a workshop titled GIS-More Than Just Making Maps are conducted as part of Libraries' Research Workshops series. ${ }^{43}$ The intended audience for these workshops includes anyone who has heard of GIS but needs help getting started. Within an hour, the basics of GIS are covered, and a few short demonstrations are provided. The DSL also delivers a presentation on data literacy and resources to the Introductory GIS class (GIS 410/510) each semester and other courses as requested by instructors.

Another service is the distribution of Esri's Virtual Campus online training access codes to patrons on request.For the period July 1, 2012-June 30, 2013, there were 2,291 codes requested, according to the Virtual Campus administrator's activity report. Most of these requests were from instructors who provide the DSL a list of student e-mail addresses, then the DSL e-mails the codes in a batch process using Python script.

Outreach. A new effort to provide guidance and consultation on data management was started in 2013 by NCSU Libraries. The work involves reviewing data management plans for grant proposals and instructing researchers on best practices for managing their electronic research files. ${ }^{44}$ Poised for continued growth, this endeavor is an extension of work with 
the Library of Congress on the North Carolina Geospatial Data Archiving Project $^{45}$ and the Geospatial Multistate Archive and Preservation Partnership. ${ }^{46}$ The librarian also serves on numerous committees affiliated with the North Carolina Geographic Information Coordinating Council, gaining opportunities for engagement and collaboration among data producers and policymakers within public and private entities throughout the state.

\section{LOOKING AHEAD}

The DSL's role has adapted to many changes, but despite continued enrollment growth in GIS-related courses and constantly growing interest in geospatial technology, the core functions of providing data and instruction in spatial analysis have remained the same.

As mentioned, online data access continues to expand, and its widely distributed nature is encouraging patrons to use the External Data Sources search tool. Meanwhile, portions of the existing data collection are growing older and much less useful for analysis of current conditions. As a result, the DSL is in the process of marking many of the data layers "legacy," and they will appear as such in the GIS Lookup data search results. This should further prompt users to consider the data options available from external sites. Although this approach is risky in that there is an increasing reliance on other services for data management, it is difficult to justify the time and resource costs of acquiring and cataloging the tremendous volumes of data already available and cataloged from external services. Moreover, it is a disservice to students to push them toward full dependency on Libraries' data collection, which can no longer be directly accessed after they graduate.

Greater data accessibility and aggregation, as well as computing advances, have displaced many of the reference queries of the past. Years ago, much time was spent guiding patrons through data projection and datum misalignments, finding basemap content, reformatting census data, and handling numerous other problems that are now almost nonissues. Instead, as geospatial data sets increasingly become valuable components within the larger analytical data realm, collaboration will continue to grow between librarians (including subject specialists in all disciplines), researchers, and IT experts to enable studies using large-extent, high-resolution data sets in new, large-scale visualization spaces within Libraries.

Map Room to Data Services at Robert E. Kennedy Library, California Polytechnic State University, San Luis Obispo

About California Polytechnic State University, San Luis Obispo

Cal Poly is part of the twenty-three-campus California State University system, located on the Central Coast of California in San Luis Obispo (SLO). 
Founded in 1901 as the California Polytechnic School, the university remains dedicated to a distinctive hands-on, learn-by-doing educational philosophy that is focused primarily on the undergraduate learning experience. Cal Poly is a medium-sized, master's degree granting university with approximately 18,000 undergraduate students, 1,000 graduate students, and 1,250 full- and part-time faculty. The university offers sixty-four bachelor's and thirty-one master's degrees, sixty-eight minors, and fourteen credentials housed in six colleges. ${ }^{47}$ Approximately $\$ 26$ million in external research funding is allocated each year in the major areas of engineering, agriculture, the sciences, architecture, environmental design, and others. ${ }^{48}$ Often, this faculty research is conducted with a high level of involvement with the undergraduate and graduate students within each discipline.

GIS courses and activities at Cal Poly are found distributed across several colleges and departments. Active departments include natural resources management and environmental sciences, the social sciences department (which houses geography courses), landscape architecture, and the city and regional planning department. Approximately ten GIS course offerings in these departments address introduction to GIS and applied GIS project courses, with additional upper division topics such as photogrammetry and remote sensing and advanced surveying with GIS applications. An additional eight to ten courses (or more) from various departments use GIS in a supporting role with examples such as watershed modeling in the civil engineering department, precision farming in horticulture and crop science, and wildlife ecology in the biology department. A common theme among these courses is the application of GIS data sets in real-world, case study problems, often with students interacting with outside professional clients to develop and present GIS information and solutions.

An interdisciplinary GIS minor is available at Cal Poly, sponsored by three departments in the College of Agriculture, Food, and Environmental Sciences: bioresource and agricultural engineering, natural resources management and environmental sciences, and horticulture and crop science. The emphasis of the minor is GIS applications in agriculture and natural resources, though students in biology, city and regional planning, landscape architecture, and others often utilize the opportunity. With GIS activities distributed across several departments on campus and without any other center for geographic research, the Robert E. Kennedy Library serves as a hub for coordinating common GIS data sets, communications, training, and other resources.

\section{GIS AND DATA SERVICES}

Data Services at the Robert E. Kennedy Library supports students and faculty in finding and using data for scholarship, teaching, and learning. During the past few years, the program has transitioned from solely GIS support toward 
a broader definition of data services to support data search and access, use and analysis, visualization, management, sharing, and curation support. In this time, the Kennedy Library has redesigned and renovated computing spaces, reclassified and hired staff for new technical support roles, and began engaging campus partners around the idea of making a space for data access and assistance within the library. In the process, Data Services has reaffirmed the library's role in serving the campus by providing central coordination and communication of common GIS and related resources.

Current staffing for Data Services includes a half-time librarian, one fulltime, twelve-month staff position for numeric and spatial data support, and two GIS peer assistants employed from the fall through spring quarters at a total fifteen hours per week. One statistics peer assistant student (funded by the College of Science and Mathematics statistics department) is also hosted in the data studio space at eight hours per week. The role of the Data Services librarian is coordinating the overall direction and development of the new Data Services program. Implementation of services is coordinated by the new full-time numeric and spatial data specialist position that began in February 2013, with additional reference assistance provided by the GIS and statistics peer assistants.

\section{COMPUTING}

In April 2012, the Kennedy Library opened the data studio, a renovated computing space with seventeen dual-monitor PC workstations, six mobile, forty-six-inch LCD monitors, moveable tables and whiteboards, and an ad hoc presentation space. The purpose of the data studio is to provide a flexible space for computing, data display and visualization, group work, peer instruction, and presentation. With these resources, the data studio serves as the home base for GIS in the library. Data studio computers have installed in them the full complement of technical computing and design software including ArcGIS 10.2, Google Earth, SketchUp, AutoCAD 2014 programs, MATLAB, SPSS, Adobe Creative Suite programs, and more. Three additional laboratory spaces available within the library also receive this technical software load, providing additional lab space where GIS courses and workshops can be conducted.

\section{Data—Collection, Discovery, Access, Storage, and Archiving}

A campus GIS file server is maintained as a central repository for commonly used GIS data sets and is available from workstations across the campus network. Data sets such as Esri Data and Maps, tutorial data sets, Spatial Labs, and Educational Datasets (Esri 2010 Census, Updated Demographics, Tapestry Segmentation, and others) are updated annually and stored here. 
Local community GIS data sets, from SLO County, SLO City, the Cal Poly Campus, and Cal Poly's 3,200-acre ranchland and school forest, Swanton Pacific Ranch, are also compiled here. Given the applied nature of many student projects, use of real-world local community GIS data sets is a common request. Licensing agreements for additional local data sets such as the SLO County parcel layer, aerial imagery, and other layers are also maintained through cooperative agreements with local government partners, allowing Cal Poly students and faculty access to otherwise expensive, licensed data sets. Approximately 200GB of imagery, elevation data sets, and vector data are stored on the GIS file server.

To provide a clearinghouse of local GIS data sets and to provide public access of GIS data sets, the Kennedy Library in partnership with the SLO GIS Users Group developed the Web-based SLO Datafinder Web site. This Web site has served as a simple and efficient destination to search and download individual data layers, made available by local government, agencies, and the university. Since its inception in 2003, new opportunities exist for delivering data sets over the Web; Data Services has renewed its role in coordinating with the community to partner in continuing to build this resource with the community of GIS users.

\section{SERVICES}

Consultation. Assisting students and faculty in finding and using GIS data sets through reference and consultation is a primary activity of Data Services staff. In the past year, GIS and data-related questions constituted approximately 390, or 10 percent, of the 3,923 general reference questions recorded by all Kennedy Library reference staff. (please see Figure 5 for details.)

General data reference questions come in several forms, ranging from simple directional guidance in locating known data sets, to more complex questions of research methodology. For the most common GIS reference questions of locating appropriate data for a particular area of interest, or converting data between data types or software packages, the GIS peer assistants are trained and available to work with students on a walk-in basis. In many cases, GIS reference requests come from students who require spatial data, but use GIS only occasionally. A common example is students in the architecture program who use elevation contours for initial site evaluation and design, but do not take courses in AutoCAD or GIS. In these instances, the GIS peer assistants can work with students to develop the information needed, but also demonstrate and show their peers GIS tools and resources that may be unfamiliar, but accessible.

For more in-depth questions, GIS consulting with the numeric and spatial data specialist is conducted on a limited basis. Research questions involving the quantifying of the compactness of the 113th U.S. Congressional 


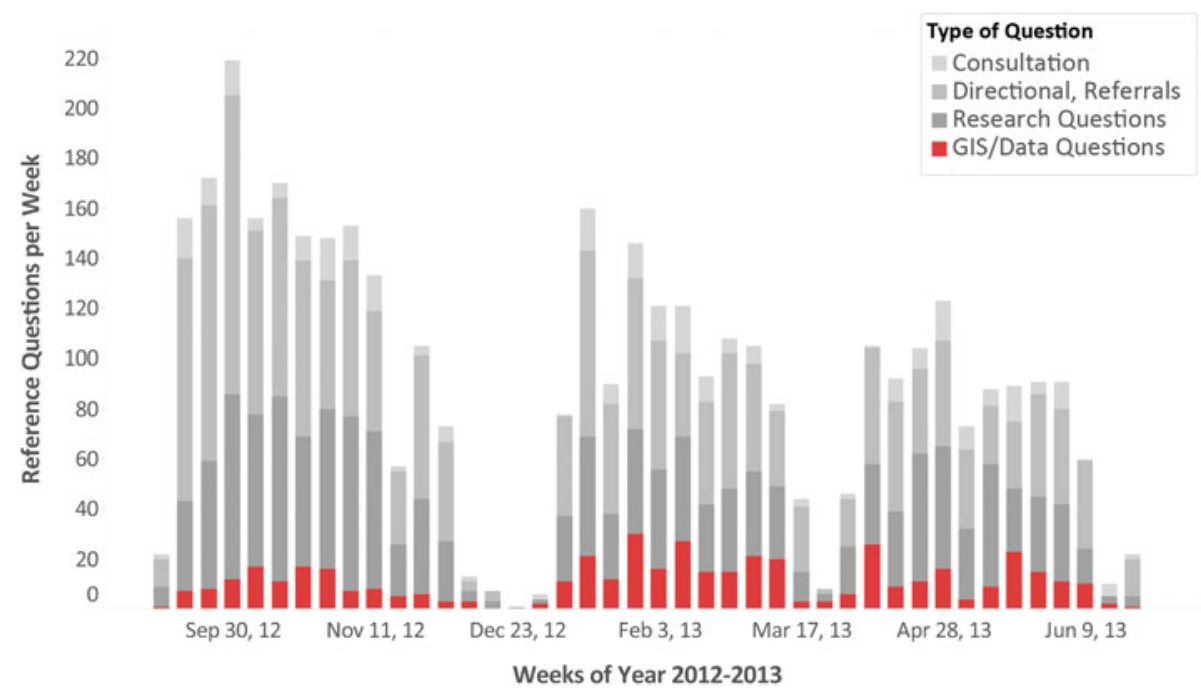

FIGURE 5 Library Reference Questions Totaled by Week for 2012-2013.

District or the application of kernel density estimation for wildlife homerange analysis require not only identification and preparation of suitable data sets, but also careful development and execution of appropriate methodology. Often, graduate student thesis projects incorporate elements of GIS analysis, but in many instances, methodological elements need to be determined. Cal Poly is a campus of relatively few graduate students, with fewer still actively engaged in spatial analysis topics. This leaves a relatively small community of practice on campus with the availability to advise graduate students on the challenging questions they face. Although one goal of Data Services is to enable student and faculty scholarship and learning, involvement with in-depth research questions must be balanced with overall service needs. Policy development is in process to address the availability and limits of GIS consultation. This is being informed by current practices and pilot projects.

Instruction and Course Support. Instructional support in the form of single-session introductory GIS overview or GIS applications for a given topic has been a component of library services in the past. At present, Data Services staff members provide only limited course involvement as they assess the program's scope and resources. In the meantime, in-class time is used as simple outreach - a way of directly informing students and faculty about the GIS resources available in the library.

Outreach. The Data Studio Presents speaker series, GIS Day, Geography Awareness Week, and the Annual Data Studio Open House are three key outreach programs supported by Data Services throughout the year to promote engagement of data and GIS users from across campus. Invited 
speakers also showcase their work with data and GIS through visual, interactive, and informal presentations. ${ }^{49}$

Geography Awareness Week and GIS Day events provide opportunities to highlight geography and GIS applications across disciplines and share with a broad audience. This year, the Kennedy Library hosted a Geography Week Map Gallery in a renovated community gallery space, bringing together both digital and print maps from a range of disciplines including transportation engineering, city and regional planning, marine biology, forestry, history, landscape architecture, and more. The map gallery reception provided an opportunity for GIS users to meet and converse around the common tools of geography as applied in a range of disciplines.

Throughout the year, the Data Studio Presents speaker series provides educational outreach for a range of data- and GIS-related topics, offering an accessible informational resource to students and faculty interested in working with data in new ways. Hosted within the data studio with an audience of approximately thirty attendees per event, the series is intended for brief intermitting discussion on a variety of topics in the rapidly advancing data and GIS fields. Past presentations have included an overview of military applications of GIS, OpenStreetMap resources, new GIS tools on the Web from Esri and Google, open data and repositories, and data management planning tools from the California Digital Library. Audio recordings of presentations as well as slides are now being combined on the presentation site Slideshare to extend access to presentation information over the Web.

\section{LOOKING AHEAD}

In the upcoming year (2014), Data Services will continue to build support and working relationships within the library, campus Information Services, institutional and community stakeholders (e.g., SLO GIS Users Group, campus GIS faculty, researchers) to more clearly define the roles Data Services might play in supporting student, staff, and faculty success. Through outreach activities such as GIS Day, the Data Studio Presents, and other events, it is clear that interest in geospatial topics is growing among a variety of disciplines. Data Services has begun preparing a strategic planning effort to engage additional library and campus constituents in defining how the program can best meet identified needs.

\section{CONCLUSION}

The variety of service models described here demonstrates that libraries continue to develop their GIS and data services programs to address the needs of their user communities while working with available resources 
and organization. Perhaps the largest difference among programs is found in the combination of disciplines served, the number of students, and the level of GIS coordination occurring in entities elsewhere in the university. Organizational structure and collaborations across campus groups, such as information technology, licensing, lab coordinators, and faculty also illustrate different opportunities and approaches to administering services. Sharing of lab spaces, part-time staff and expertise, and ITS occur in different ways as informed by the structure of administrative units.

The service areas in which the five programs differ most include collection development and data discovery and access solutions. No standard platform exists for cataloging and making GIS data sets available. These programs demonstrate some valuable approaches in integrating these data sets into existing access systems. The challenges associated with spatial data discovery and access are echoed throughout this paper. These five programs have met the challenges with interesting hybrid solutions that provide users access to spatial data available online and from the library that include thematic listings on Web sites and Libguides, use of social bookmarking, discovery and access through the library catalog, a data portal for the library's spatial data collection, and a data portal that provides federated searching of several large data providers' collections of publicly accessible data.

Although there are some differences among the organizational structures and the ways each program provides data to users, the five programs share many similarities. Each program works to increase the presence, awareness, and use of GIS and data on campus. All program administrators have demonstrated their deep understanding of the needs and resources generated by campus GIS stakeholders and have found mutually beneficial ways to work together. It is

apparent to anyone who does GIS on campus, there are a myriad of individual efforts, but [a recognition that the] consolidation of. .. collective strengths offers tremendous opportunities to fortify existing geospatial activities and extend to a variety of new ones. (Mason and Harvey 2009, 5)

Librarians and GIS specialists from these programs have collaborated with other units on their campuses to facilitate the dissemination of GIS software and online training, to provide training and assistance, and to improve shared spaces on campus.

Because these programs have similar goals, they offer similar services. GIS services include outreach and provision of spatial resources, consulting with faculty from diverse disciplines, and giving advice to students (Mason and Harvey 2009, 1). These activities vary somewhat from campus to campus but generally include programming and teaching workshops on GIS and data management, regular use of listservs, invited speaker seminars, GIS 
Day and Geography Awareness Week activities, and maintaining awareness of services and activities at other universities.

One other service area common to all five programs is instruction, which is evolving from basic software training to comprehensive digital and data literacy programs. Librarians are being asked to support students as they become content consumers and content creators through pedagogical approaches that adopt and adapt to the rapidly changing digital information environment (Association of College and Research Libraries 2013, 5). To provide this support, librarians are providing data management workshops, consultating on data management plans, and assisting researchers with data collection inquiries during consultations.

In addition to offering similar services, all programs are in high demand at their universities. Older programs report consistently high demand, while newer ones report rapid growth. One reason for the high demand is the increasingly diverse subject areas and disciplines using data and GIS. As was noted in several programs' sections, the library is a central and communal resource for people on campus needing GIS and data services. It is the best place for those whose disciplines do not have a large focus on data or GIS. One way staff are accommodating the needs of new users is through Webmapping tools and Web-based GIS technology, which is easier to use than desktop GIS and is increasingly useful for analysis.

Several sections discuss ways in which libraries have improved work areas for their users by providing work spaces conducive to collaboration and laptop use. As geospatial data continue to become increasingly valuable within the larger analytical data realm, it is important for libraries and universities as a whole to enable collaborative research and analysis. Libraries are doing this in part by providing space and making available relevant services to researchers from all disciplines.

Another recurring theme throughout the sections is the importance of data preservation. As technology evolves and memory-intensive data sets become more readily available, librarians must continue assessing the best methods and platforms for data preservation to benefit a progressively diverse patron base. Each section discussed data preservation or the availability of a repository for researcher output.

Although the growing demand for staffing, services, hardware infrastructure, and Web services has been addressed in different ways by each university library, all share the same underlying goals to provide GIS and data services to support research and teaching at their universities. These challenges and opportunities are best faced not only through collaboration among campus stakeholders, communities and local organizations, but also through collaboration among GIS and data services librarians, as evidenced within this paper. This group of librarians and GIS specialists from five universities came together to create a community of practice, a forum to share advice and approaches for responding to the rapidly changing GIS 
landscape in academic libraries. Sharing feedback and learning from the stumbling blocks encountered across the various campuses will be key to continue developing useful services for researchers and patrons (Abresch, 2008). This informal partnership provides a support system and an opportunity to collaborate on programming such as GIS Day events. GIS and data are structured with integrated components consisting of "hardware, software, data, people, and methods" (Dixon 2006) which provides an effective framework for collaboration. This ongoing collaboration will be of great future benefit, as it will decrease the time necessary to assess the needs, infrastructure, opportunities, and implementation of data services on campus.

\section{NOTES}

1. The University of North Carolina at Chapel Hill Office of Institutional Research and Assessment. "General Information about the University." http://oira.unc.edu/facts-and-figures/general-informationabout-unc/, The Graduate School at the University of North Carolina at Chapel Hill. "For Prospective Students." http://gradschool.unc.edu/prospective.html

2. The University of North Carolina at Chapel Hill University Libraries. "About UNC Libraries." http://library.unc.edu/about/.

3. The University of North Carolina at Chapel Hill Office of the University Registrar. "Schedule of Classes." http://registrar.unc.edu/courses/schedule-of-classes/\#search

4. The University of North Carolina at Chapel Hill Information Technology Services. "Carolina Computing Initiative." http://cci.unc.edu/about-cci/

5. "LibraryH3lp," LibraryH3lp, accessed November 10, 2013, http://libraryh3lp.com/

6. "GIS \& Data Services," The University of North Carolina at Chapel Hill University Library, accessed November 10, 2013, http://library.unc.edu/services/data/

7. "Course Guide for GIS Classes," The University of North Carolina at Chapel Hill University Library, accessed November 10, 2013, http://guides.lib.unc.edu/gis

8. "uncgis," Nine Fives Software, accessed November 10, 2013, https://pinboard.in/u:uncgis

9. "Spatial Data Online," The University of North Carolina at Chapel Hill University Library, accessed November 10, 2013, http://guides.lib.unc.edu/spatialdata

10. "About the Repository," The University of North Carolina at Chapel Hill University Library, accessed November 10, 2013, https://cdr.lib.unc.edu/scontent/aboutPages/aboutTheRepository.xml

11. "GIS Assistance," The University of North Carolina at Chapel Hill University Library, accessed November 10, 2013, http://library.unc.edu/services/data/gis-assistance/.

12. "YouCanBook.Me," YouCanBook.Me, accessed November 10, 2013, https://youcanbook.me/

13. "For Graduates and Post Docs: Graduate Research Consultant (GRC) Program," The University of North Carolina at Chapel Hill Office for Undergraduate Research, accessed November 6, 2013, http://www.unc.edu/depts/our/grads_post/grads_grc.html

14. "Geographic Information Systems (GIS) Services: USDA Historical Aerial Photos," University of North Carolina at Chapel Hill University Library, accessed November 10, 2013, http://www2.lib.unc.edu/reference/gis/USDA/index.html

15. "Service Credits Overview," Esri, accessed January 8, 2014, http://www.Esri.com/software/ arcgis/arcgisonline/credits

16. Texas A\&M University. "Facts About Research." http://www.tamu.edu/about/facts/ research.html

17. Texas A\&M University. "Facts About Research." http://www.tamu.edu/faculties

18. Ibid, and Texas A\&M University. "Resources for Faculty Members." http://www.tamu. edu/faculties/

19. Texas A\&M University, "Texas A\&M University Facts" http://www.tamu.edu/ about/facts/history.html

20. Texas A\&M University, "Texas A\&M University Facts" and "History of the University." http://www.tamu.edu/about/facts/history.html, http://www.tamu.edu/about/facts/ 
21. Texas A\&M University Geography Department. "GIS/RS Certificate Program." http://geography.tamu.edu/research/giscience-and-remote-sensing/gis-rs-certification

22. Texas A\&M University. Map and GIS Collections and Services. "GIS and Remote Sensing Courses Offered At Texas A\&M University." http://library.tamu.edu/pdfs/GIS\%20Courses-1Column.pdf

23. http://www.google.com/about/company/history/

24. New York University. "Fast Facts." http://www.nyu.edu/about/news-publications/nyufacts/fast-facts.html

25. New York University. "History of NYU." http://www.nyu.edu/about/news-publications/ history-of-nyu.html

26. http://cusp.nyu.edu/

27. New York University. Institute of Fine Arts. "Current IFA Projects at Abydos." http://www.nyu.edu/gsas/dept/fineart/academics/abydos/abydos-current.htm

28. http://furmancenter.org/research/sonychan

29. http://furmancenter.org/research/publications/c/state-of-new-york-citys-subsidized-housing

30. http://nyu.libguides.com/researchcommons

31. http://nyu.libguides.com/dataservices

32. http://nyu.libguides.com/digitalstudio

33. http://library.nyu.edu/vbl/

34. http://nyu.libguides.com/science

35. http://nyu.libguides.com/content.php?pid $=169769 \&$ sid $=1723559$

36. Method: when a GIS query is addressed and resolved, Data Services records it as one GIS interaction. If the query requires threaded/multiple interactions, it is still recorded as one interaction, unless the requirement of the query has changed.

37. NC State University. 2013. "NC State University at a Glance." http://www.ncsu.edu/about-ncstate/quick-view/

38. Web content for the Geovisualization Laboratory is still under development, as of the writing of this article. Presently, more information can be found at http://cnr.ncsu.edu/blogs/cga, http://www. ncsu.edu/project/cnr/dev/ceo/, and http://cnr.ncsu.edu/prtm/research/visualization_lab.php

39. Open Source Geospatial Research and Education Laboratory Web site: http://gis.ncsu. edu/osgeorel

40. NC State University. Office of the Provost, 2012. "Chancellor's Faculty Excellence Program." http://provost.ncsu.edu/special-initiatives/chancellors-faculty-excellence/

41. Cheshire, Heather, e-mail message to author, October 1, 2013.

42. GIS computer software list: http://www.lib.ncsu.edu/gis/software.html

43. Libraries' Research Workshops Web site: http://www.lib.ncsu.edu/researchworkshops

44. Data Management Planning Web site: http://www.lib.ncsu.edu/guides/datamanagement

45. Geospatial Data Archiving Project Web site: http://www.lib.ncsu.edu/ncgdap

46. Geospatial Multistate Archive and Preservation Partnership Web site: http://www.geomapp.net

47. http://calpolynews.calpoly.edu/quickfacts.html

48. http://research.calpoly.edu/annualreport.html

49. http://libguides.calpoly.edu/datastudio

\section{REFERENCES}

Abresch, John. 2008. Integrating geographic information systems into library services: A guide for academic libraries. Hershey, PA: Information Science Publishing.

Adler, Prudence S. 1995. Special issue of geographic information systems (GIS) and academic libraries: An introduction. Journal of Academic Librarianship 21(4): 233-235, doi:10.1016/0099-1333(95)90002-0.

Adler, Prudence S. 1997. An introduction-Where are we heading? Journal of Academic Librarianship 23(6): 447-448, doi:10.1016/S0099-1333(97)90168-3.

Association of College and Research Libraries. Working group on intersections of scholarly communication and information literacy. Intersections of scholarly 
communication and information literacy: Creating strategic collaborations for a changing academic environment. Chicago: Association of College and Research Libraries, 2013. http://www.ala.org/acrl/sites/ala.org.acrl/files/content/publicati ons/whitepapers/Intersections.pdf

Association of Research Libraries. 1999. The ARL Geographic Information Systems Literacy Project: a SPEC kit. Washington, DC: Association of Research Libraries, Office of Leadership and Management Services.

Aufmuth, J. 2006. Centralized vs. decentralized systems: Academic library models for GIS and remote sensing activities on campus. Library Trends 55(2): 340-347.

Dixon, Janet B. 2006. Essential collaboration. Journal of Map \& Geography Libraries 2(2) (July 13): 5-20, doi:10.1300/J230v02n02_02.

Donnelly, Francis P. 2010. Evaluating open source GIS for libraries. Library Hi Tech 28(1): 131-51, doi:10.1108/07378831011026742.

Florance, Patrick. 2006. GIS collection development within an academic library. Library Trends 55 (2): 222-34, doi:10.1353/lib.2006.0057.

Houser, Rhonda. 2006. Building a library GIS service from the ground up. Library Trends 55(2): 315-326.

Kinikin, JaNae, and Keith Hench. 2005. Survey of GIS implementation and use within smaller academic libraries. Issues in Science and Technology Librarianship (42), doi:10.5062/F4SX6B56.

March, Gregory H. 2011. Surveying campus GIS and GPS users to determine role and level of library services. Journal of Map \& Geography Libraries 7(2): 154-183, doi:10.1080/15420353.2011.566838.

Mason, Steven and Francis Harvey, eds. (2009) Geospatial Consortium: Collaborative Geospatial Activities at University of Minnesota.

Morris, Steven P. 1999. Geodata across the campus network: Library GIS data services at North Carolina State University. Paper presented at the Esri International Users Conference, San Diego, California, July 26-30.

Salem, J. A. 2005. Spatial data collections and services, SPEC Kit 291 Washington, DC: Association of Research Libraries, Office of Leadership and Management Services.

Scarletto, Edith. 2011. Collection development guidance through reference inquiry analysis: A study of map library patrons and their needs. Journal of Map $\varepsilon$ Geography Libraries 7(2): 124-37, doi:10.1080/15420353.2011.566835.

Stoltenberg, Jaime, and Abraham Parrish, eds. (2006). Geographic information systems and libraries. Special Issue, Library Trends 55(2): 217-221.

Sweetkind-Singer, Julie, and Meredith Williams. 2001. Supporting the information needs of geographic information systems (GIS) users in an academic library. Science \& Technology Libraries 21(3-4): 175-190, doi:10.1300/J122v21n03_11.

Weimer, Katherine H. 2008. Map, GIS and cataloging / Metadata Librarian Core Competencies. MAGERT ALA Map and Geography Round Table. http://www. ala.org/magirt/sites/ala.org.magirt/files/content/publicationsab/MAGERTCoreC omp2008_rev2012.pdf.

Weimer, Katherine H., and Pete Reehling. 2006. A new model of geographic information librarianship: Description, curriculum and program proposal. Journal of Education for Library and Information Science 47(4): 291-302, doi: $10.2307 / 40323822$. 


\section{APPENDIX A. Additional Resources}

ALA Maps and Geospatial Information Round Table (MAGIRT), http://magirt.ala.libguides.com/resources

Aufmuth, Joe. 2006. Centralized vs. distributed systems: Academic library models for GIS and remote sensing activities on campus. http://hdl.handle.net/2142/3678

Bennett, Terrance B., and Shawn W. Nicholson. 2007. Research libraries: Connecting users to numeric and spatial resources. Social Science Computer Review 25(3): 302-318.

Campbell, James. 2011. Survey: Contributing or using spatially-referenced data in commons environments. Part of unpublished dissertation, Department of Spatial Information Science and Engineering, University of Maine.

Davie, D. Kevin, James Fox, and Barbara Preece. 1999. The ARL Geographic Information Systems Literacy Project. SPEC Kit 238. Washington, DC: Association of Research Libraries.

Florance, Patrick. 2006. GIS collection development within an academic library. Library Trends 55(2): 222-234.

Gluck, Myke and Lixin Yu. 2000. Geographic information systems: Background, frameworks, and uses in libraries. Advances in Librarianship 23: 1-38.

http://www.nmc.org/publications/2013-horizon-report-higher-ed

Hoover, Jasmine. 2012. GIS Collaborations in Saskatchewan: SGIC and the University of Saskatchewan Library. Journal of Map \& Geography Libraries 8: 68-79.

Houser, Rhonda. 2006. Building a library GIS Service from the ground up. Library Trends 55(2): 315-326.

Johnson, Larry, Samantha Adams, Malcolm Cummins, Victoria Estrada, Alex Freeman, and Holly Ludgate. 2013. The NMC Horizon Report: 2013 higher education edition. http://www.nmc.org/publications/2013-horizon-report-higher-ed

Kelly, Linda. 2013. Maps, libraries and the 'GIS librarian': An informal review of international cartographic libraries. South African Journal of Geomatics 2(2): $163-174$.

Kinikin, JaNae, and Keith Hench. 2005. Survey of gis implementation and use within smaller academic libraries. Issues in Science and Technology Librarianship 42.

March, Gregory H. 2011. Surveying campus GIS and GPS users to determine role and level of library services. Journal of Map \& Geography Libraries 7(2): 154-183.

Moulder, Cathy. 2014. Current literature on geographic information systems and libraries. McMaster University Libraries. Lloyd Reeds Map Collection. http://library.mcmaster.ca/maps/current-literature-gis-and-libraries

Newton, Mark P., C. C. Miller, and Marianne Stowell Bracke. 2011. Librarian Roles in institutional repository data set collecting: Outcomes of a research library task force. Collection Management 36: 53-67.

Olson, John A. 2004. Library-based GIS labs. Journal of Map \& Geography Libraries 1(1): 75-88.

- 2009. Data as a Service: Are we in the clouds? Journal of Map \& Geography Libraries 6(1) (December 31): 76-78.

Parrish, Abraham. 2006. Improving GIS consultations: A case study at Yale University Library. Library Trends 55 (2): 327-339. 
Peters, Christie, and Anita Riley Dryden. 2011. Assessing the academic library's role in campus-wide research data management: A first step at the University of Houston. Science and Technology Libraries 30(4): 387-403.

Salem, J. A. 2005. Spatial data collections and Services. SPEC Kit 291. Washington, DC: Association of Research Libraries.

Scarletto, Edith. 2011. Collection development guidance through reference inquiry analysis: A study of map library patrons and their needs. Journal of Map $\mathcal{E}$ Geography Libraries 7(2) (May 1): 124-137.

- 2013. Data driven program planning for GIS instruction. Issues in Science and Technology Librarianship 73.

Salem, J. A. 2005. Spatial data collections and services. SPEC Kit 291. Washington, DC: Association of Research Libraries.

Sweetkind-Singer, Julie, and Meredith Williams. 2001. Supporting the information needs of geographic information systems (GIS) users in an academic library. Science \& Technology Libraries 21(3-4): 175-190.

Tenopir, Carol, Ben Birch, and Suzie Allard. 2012. Academic libraries and research data services: Current practices and plans for the future. An ACRL White Paper.

Todd, Julia L. 2008. GIS and libraries: A cross-disciplinary approach. Online 32 (5): 14-18.

Vardakosta, Ifigeneia, and Sarantos Kapidakis. 2011. Geographic collections development policies and GIS services: A research in US academic libraries' Websites. In First Workshop on Digital Information Management, Corfu, Greece, 30-31 March, 2011.

Vinopal, Jennifer, and Monica McCormick. 2013. Supporting digital scholarship in research libraries: Scalability and sustainability. Journal of Library Administration 53(1): 27-42. 